\title{
Ensino Superior e Universidade \\ no Brasil
}

MARLENE CABRERA DA SILVA

Técnica de Educação e Assessora do Departamento de Assuntos Universitários do MEC

1. Cultura Humanística; 2. Profissionalização do Ensino Superior; 3. A Idéia de Universidade; 4. A Universidade na República; 5 . Reforma Universitária.

no Em 1968, em suas "Reflexões sobre a Educação Superior no Brasil", H. W. Hoge, membro da USEAPES, fazia a seguinte observação:

"A afirmação descritiva mais exata que se pode fazer acerca da Universidade Brasileira é que ela não existe. Isto quer dizer que o Brasil nunca teve e ainda hoje não tem uma "Universidade" no sentido de um conjunto de cursos profissionais integrados, com um componente preparatório básico e comum... Todos os esforços para alterar o padrão estrutural estabelecido estão destinados ao fracasso, enquanto as faculdades isoladas continuarem a existir e a proliferar como instituições que concedem diplomas, e enquanto as novas "Universidades" forem criadas e reconhecidas pela aglomeração de tais faculdades já existentes". ${ }^{1}$

cios De fato, nossa tradição tem sido de escolas independentes, Ceber ente defensoras de sua autonomia, organizadas para reministrunos graduados no curso secundário e segregá-los para formistrar-lhes preparo profissional em algumas modalidades de e as que se seguiram, constituíram-se pela reunião nominal de ceralas pré-existentes que, apesar de congregadas, permaneram estanques e auto-suficientes. Nestas circunstâncias, pou-

In Re HOGE, H. W. - Reflexões sobre a Educação Superior no Brasil EAPES rório da Equipe de Assessoria do Planejamento do Ensino Superior PES - MEC - 1969 — pág. 577. 
cas puderam passar de reitorias, montadas para serviços centralizados de orçamento e administração, para atos solenes de abertura e encerramento do ano letivo e para debate, ainda tímido, sobre a inviabilidade da própria estrutura e a necessidade de proceder-se à reforma universitária.

No Brasil, "é esta tradição secular que se tem constituído no grande empecilho à plena concretização da idéia universitária". 2 A Universidade de Coimbra, primeiro modelo para nossas experiências de educação superior, fora uma Universidade de escolas profissionais, e o que trouxemos, até hoje, da experiência de outros povos, não atingiu a essência do processo universitário, e o resultado aí está: "o que se veio a chamar de Universidade Brasileira não chegou a ser universidade, na acepção técnica da palavra, por inexistir estrutural e funcionalmente como tal, nem é brasileira, como pode e deve ser, por não estar em equação com as características atuais da realidade nacional". ${ }^{3}$

Alguns fatos e muitas reflexões nos ajudam a compreender como um país pode, durante um longo período de sua história, entreter a sua civilização e fazer prosperar sua cultura, sem possuir o que nos grandes países do mundo era o próprio instrumento dos progressos literários, filosóficos e científicos: as Universidades.

\section{CULTURA HUMANISTICA}

As circunstâncias do Brasil-Colônia fizeram com que os papéis intelectuais se desenvolvessem, primeiramente, sob a influência do clero. A organização da sociedade colonial brasileira, baseada no princípio de estratificação interética, não apresentava as condições sociais e culturais indispensáveis como suporte ao desenvolvimento do saber racional. Em conseqüência, coube à Companhia de Jesus exercer, nesse período, uma influência contínua e profunda na construção do sistema intelectual da época, transportando para o Brasil um tipo de saber que não encontrava fundamentos na ordem social existente.

Segundo a "Ratio Studiorum", publicada em 1599, e em que se corporificavam as regras pedagógicas de Santo Inácio, o plano completo de estudos da Companhia de Jesus devia

2 SUCUPIRA, Newton - A Reestruturação das Universidades Federais - Rev. bras. Est. Ped. MEC/INEP - no 111 - 1968 - pág. 88.

3 CHAGAS, Valnir - A Reforma Universitária e a Faculdade de Filosofia - Rev. bras. Est. Ped. n? 83 - Rio de Janeiro - MEC/INEP 1961 - pág. 38. 
abranger o curso de Letras Humanas, o de Filosofia e Ciências (Artes) e o de Teologia e Ciências Sagradas. Foi o curso de Letras que mais se propagou na Colônia. Em 1572, instalava-se no Colégio da Bahia o primeiro curso de Artes nos moldes do Colégio Romano, chegando a conceder licenciaturas culturais Q a ter seus alunos admitidos na Universidade de Coimbra para o último ano do Colégio de Artes, reconhecidos os três primeiros feitos no Brasil.

Era, pois, natural que os jesuítas desejassem fundar uma universidade brasileira no tempo em que tinham a responsabilidade e a direção dos estudos no Brasil.

O "meio cultural era fraco", alegavam os relatórios dirigidos à Metrópole, para empreendimento de tamanho vulto; entretanto, não era melhor o ambiente do México quando lá se instalou, em 1553, a Universidade Real e Pontífica, nem mesmo a América do Norte apresentava em 1636 - data da criação da Universidade de Harvard - um quadro cultural florescente. Assim, fecharam-se todas as perspectivas para a criação, no Brasil colonial, de cursos superiores destinados à preparação para as profissões liberais.

Toda cultura brasileira, no período colonial como no século XIX, está nos lineamentos traçados pelos jesuítas, com seu ensino de humanidades com efeitos tão profundos e persistentes que não se apagaram durante a ausência destes do país por mais de 80 anos. Nossa cultura superior, que até 1830 quase dependia ainda de Coimbra, não perdeu, pelo seu caráter profissional mais acentuado, nem o gosto pela cultura geral, nem o espírito literário, nem aquela curiosidade mais extensa que nos leva a interessar-nos, ainda que superficialmente, pelos problemas mais variados.

\section{PROFISSIONALIZAÇÃO DO ENSINO SUPERIOR}

Com a expulsão dos jesuitas de todos os territórios portugueses, em 1759, verificou-se uma grande lacuna no ensino brasileiro. Da reforma da Universidade de Coimbra empreendida Por Pombal, o Brasil não colheu senão os benefícios que delam resultar para os jovens brasileiros que foram a Portugal reorpletar seus estudos. Se a ação distante da Universidade, extenizada segundo novas tendências, não foi suficiente, em nantes a o profundidade, para reduzir as preocupações domitruçã de uma educação literária, serviu para introduzir a ins1800 , utilitária no Brasil. O Seminário de Olinda, fundado em adotando um currículo mais realístico, representa a pri- 
meira repercussão brasileira da reforma universitária coimbrã de 1772 e das idéias liberais da filosofia da ilustração que irradiavam da França.

A ideologia da Revolução francesa propagava por toda parte um preconceito antiuniversitário. Todo conhecimento não utilitário deveria ser desprezado. O que importava, porém, no clímax revolucionário europeu, favorecido pelo desenvolvimento das ciências e pelo declínio do prestígio das velhas universidades, era a aquisição de uma certa ciência limitada, de uma profissão.

Não se sabe até que ponto essas tendências à profissionalização do ensino superior, favoráveis às escolas especiais $e$ hostis à universidade, teriam influenciado na orientação que $D$. João VI imprimira ao ensino na Colônia. Foram criadas escolas que visavam, antes de tudo, às formações especializadas e à preparação de pessoal capaz de atender ao serviço público. Nessa época surgiam as primeiras pressões no sentido de se adestrar um setor maior de população para o exercício de tarefas administrativas e políticas ou para enfrentar necessidades que emergiam com a expansão econômica e com o crescimento demográfico. Eram necessários homens instruídos e técnicos em medicina, economia, agricultura e indústria; fundaram-se, na Bahia, o Curso de Cirurgia (1808), a Cadeira de Economia (1808), o Curso de Agricultura (1812), o de Química (1817), e o de Desenho Técnico (1818) e, no Rio de Janeiro, o Curso de Cirurgia (1809), o Laboratório de Química (1812), o Curso de Agricultura (1814), os quais se destinavam a suprir a deficiência absoluta de técnicos que satisfizessem as necessidades do meio brasileiro, em transição para um tipo de vida urbana $e$ industrial, e para melhor organização da economia agrícola
do País.

Proclamada a Independência e constituido o Império, a educação nacional foi matéria, na Constituinte de 1823 , de calorosos debates que visavam, especialmente, a organização de uma universidade no País, marcando, até certo ponto, uma reviravolta na política educacional empreendida por D. Joäo VI. A iniciativa procedeu de um grupo de brasileiros matriculados na Universidade de Coimbra, sendo representados pelo deputado José Feliciano Fernandez Pinheiro, mais tarde Visconde de São Leopoldo, que propôs "que no Império do Brasil se crie quando antes uma Universidade, pelo menos, para assento da qual parece dever ser preferida a cidade de São Paulo, pelas vantagens naturais e razões de conveniência Geral". As- 
Cendeu-se, com a apresentação do projeto por Ribeiro de Andrade, a luta regionalista: discutia-se não só o número delas, se uma, duas ou três, mas também a localização respectiva. Finalmente, aprovado o projeto de criação de duas universidades, uma em São Paulo outra em Olinda, em novembro de 1823 , morreu definitivamente essa iniciativa com golpe de Estado que, oito dias depois, dissolvia a Assembléia Constituinte.

Pode ser considerada como outra tentativa frustrada de organização universitária a criação do Instituto Brasilico. A idéia do deputado Manuel Ferreira da Câmara e Bittencourt de Sá era de reunir, em uma só instituição, as quatro escolas superiores já existentes no Rio de Janeiro, isto é, a Academia Médico-Cirúrgica, a Academia Militar, a Academia de Marinha e a Academia de Pintura. A esse conjunto seriam acrescidos o Museu de História Natural, o Jardim Botânico, o Observatório a Biblioteca Pública.

A única providência nesse sentido do Brasil independente, no entanto, foi a criação dos cursos jurídicos, em 11 de agosto de 1827, um deles com sede no Mosteiro de São Bento, em Olinda, e o outro instalado no Convento de São Francisco, em São Paulo. No meio do século, em 1854 , esses cursos se organizaram em Faculdades, transladada a de Olinda para Recife.

No período Regencial que se segue, o Ato Adicional aprovado em 6 de agosto de 1834 determinou às Assembléias provinciais o encargo de regular a instrução primária e secundária, ficando dependentes da administração nacional o ensino superior em todo o País e a organização escolar do Município Neutro.

D. A profissionalização do ensino superior, inaugurada por Adicioão VI, e a fragmentação do ensino, consagrada pelo Ato um séal, deviam marcar profundamente, através de mais de titu século, a fisionomia característica de nossa educação inscursonal, em que falharam todas as tentativas para alterar o de sua evolução. Certamente, a ausência, na educação ção País, de um pensamento coletivo ou de unidade de orientatua, não era mais do que uma das expressões do estado flutuante e molecular da sociedade, que resultou do caráter fragmentário de nossa formação social e das divergências fundaculturais de interesses e de idéias, ligados às diferenças de nivel sociais. 


\section{A IDÉIA DE UNIVERSIDADE}

A idéia de unidade e de universalidade do ensino, que parecia prevalecer sobre a das formações especializadas, não chegou a determinar, no Império, a mais leve inflexão na politica anterior, cujo espírito de continuidade não se interrompeu durante mais de um século, em que o ensino superior permaneceu inteiramente dominado pelo espírito profissional e utilitário. A única instituição de cultura geral, criada desde a Independência até a República, foi o Colégio Pedro II, fundado em 1837, representando os estudos literários e desinteressados, mantendo sempre, em todas as transformações por que passava, o seu caráter de cultura básica necessária às elites dirigentes do País.

Mantinha-se o tabu, oriundo dos tempos coloniais, de que a criação de universidade poderia concorrer para o rompimento dos laços que nos uniam às Cortes de Lisboa. Assim, em 1836, o Ministro José Inácio Borges mostrou-se adverso às sugestões que lhe foram feitas no sentido dessa criação. Achava que a concentração universitária poderia determinar ciúmes provinciais que seriam "sem dúvida aproveitados pelos perturbadores da ordem pública para justificarem suas criminosas tentativas". Outros, como os Ministros Antônio Paulino Limpo de Abreu, Francisco de Paula de Almeida Albuquerque, Aires Coelho e Bernardo Pereira de Vasconcelos, tornaram-se apologistas da idéia universitária, sendo muito significativo o relatório deste último, reproduzido na obra de Ernesto de Souza Campos: "Tratando-se em globo dos principios daqueles estabelecimentos, não posso deixar de render a homenagem da minha admiração ao voto uníssono dos meus antecessores sobre a conveniência da reunião dos estabelecimentos de instrução subordinada à Secretaria de Estado de Negócios do Império, com outras já existentes entre nós e com mais alguns que se devam criar em um corpo de Universidade, na capital do Império". 4

Sucediam-se as propostas e os substitutivos. Os professores da Faculdade de Medicina da Bahia insurgem-se contra tais projetos; entendiam os professores baianos que a criação da Universidade do Rio de Janeiro daria golpe mortal na instrução da província, e reclamavam diante "da injustiça clamo" rosa que se irroga à Bahia, privá-la do único estabelecimento de ensino superior que nela existe". A Câmara dos Senadores

4 CAMPOS, Ernesto de Souza - A Educação Superior no Brasil Rio de Janeiro - MEC - 1940, pág. 236. 
não mais cuidou de dotar o Brasil de uma universidade. Em 1847 , o Visconde de Goiana declara que o projeto é ocioso, dispendioso e inútil. Desejaria um plano geral para a instrução nacional, não só primária, como secundária e de graus acadêmicos; chegou a apresentar um projeto de reforma geral de toda a educação nacional.

Em 1870, outro projeto, de autoria do Conselheiro Paulino José Soares de Souza, propunha a criação, na capital do Império, de uma Universidade que compreendia quatro faculdades: direito, medicina, ciências naturais, matemática e teologia. Como se vê, a idéia de reunião de estabelecimentos isolados para constituírem a "Universidade", persistia.

Presidido pelo Conde D'Eu, realizou-se em 1882 um Congresso de Instrução ao qual o Imperador Pedro II deu extraOrdinária importância. Nesse Congresso o Conselheiro Antônio Oliveira Almeida alegou que "universidade é uma coisa obsoleta e o Brasil como País novo, não pode querer voltar atrás para constituir a universidade, deve manter suas escolas especiais, porque o ensino tem de entrar em fase de especialização profunda; a velha universidade não pode ser restabelecida". ${ }^{5}$ Para a época, seu argumento demonstrava certa lucidez. O BraSil, nesses primeiros séculos, apesar de não ter tido universidade em seu território contou com a de Coimbra que, como universidade tipicamente medieval, encontrava-se plenamente decadente face às transformaçõs sociais e os novos rumos tomados pela ciência e pesquisa. O que, provavelmente, o ConSelheiro Almeida desconhecia era o renascimento da Universidade, com Humboldt, na Alemanha, em princípios do século $X \mid X$, operando-se a grande renovação do ensino universitário. Infelizmente, essa nova organização universitária, a qual serve vem verdadeiro modelo às universidades atuais do mundo, não vem refletir-se no Brasil.

do O Imperador Pedro II, homem razoavelmente culto e inclinarior para as coisas intelectuais, não abriu uma só escola supeuniversiasil, como também resistiu à idéia de criação de uma do 1 rsidade até sua última "Fala do Trono", em 3 de maio do aos 1889 , quando solicitou a criação de um Ministério destinatécnic negócios da instrução pública, a fundação de escolas 

ganizaçăo do Conselho Superior de Instruçăo Púa, Antônio de uma Universidade; or- Pareceres do Congre Superior de Instrução Pública ( $2^{\mathrm{a}}$ e $3^{\mathrm{a}}$ questões) Atas Pareceres do Congresso de Instrução do Rio de Janeiro de $1882-2^{\text {a }}$
Parto - RJ. Imp. Nacional, 1884 . 
instituição de duas universidades: uma ao norte e outra ao sul do País.

As aspirações largas e ambiciosas, da última "Fala do Trono" em 1889, não tiveram para apoiá-las nem uma mentalidade nova, nem uma realidade social maleável e plástica, nem um surto econômico que favorecesse profundas transformaçőes no sistema educativo brasileiro.

Não foi apenas a influência conservadora que no Império se opôs à criação de uma universidade brasileira: havia, na classe governante, a idéia de que a sociedade que se estava construindo ia ser uma sociedade utilitária, uma sociedade de trabalho e, como tal, não ganharia muito em receber os ornamentos e as riquezas da "velha educação universitária".

Assim, ficou o Brasil esperando até 1920, quando a Universidade, finalmente, surgiu, embora já bastante cheia de imperfeições.

\section{A UNIVERSIDADE NA REPÚBLICA}

Não foi menos desordenado, no início da República, o movimento pela idéia de Universidade, manifesta reiteradas vezes ém estudos e projetos, condenados igualmente, uns após outros. ao abandono total. "Por ela não se travou batalha decisiva nem no império nem na primeira república; e, se foi por vezes objeto de debates parlamentares, não se promoveu, por ela, nenhuma campanha tão vigorosamente sustentada que chegasse a inseri-la no real. A conspiração contra essa idéia devia ser muito maior, mais profunda e mais eficaz, do que os combates que por ela se feriram. ${ }^{6}$

No ano de 1915, processou-se a Reforma Carlos Maximiliano que, através de um dispositivo inteligente, permitia que "o governo federal quando julgasse oportuno", reuniria em Universidade a Faculdade de Medicina, a Escola Politécnica $e$ uma das Faculdades Livres de Direito, existentes na capital da República. O presidente do Conselho Superior do Ensino assumiria as funções de reitor. A "oportunidade" surgiu cinco anos depois, quando o governo Epitácio Pessoa executa aquela altorização, pelo decreto no 14.343 , de 7 de setembro de 1920 , criando a Universidade do Rio de Janeiro, que a partir de 1937, passa a chamar-se Universidade do Brasil, vindo, recentemente, a adquirir a denominação de Universidade Federal
do Rio de Janeiro.

4. 6 AZEVEDO, Fernando de - A Universidade de Sã̃o Paulo in a Edư cação Entre Dois Mundos - S. Paulo - Melhoramentos - pág. 125. 
Composta, de início, das três faculdades previstas em 1915, já nasceu defeituosa como organização universitária apenas um rótulo para nomear a reunião de instituições préexistentes de formação profissional. Como não houve preoCupação alguma de se estabelecer uma estrutura universitária com serviços de ensino e pesquisa comuns e integrados, o desfecho da questão ficou longe de corresponder aos projetos até então elaborados.

tam o propósito de corrigir as limitações do modelo adotado em 1920, o Decreto n? 19.851, sobre a organização do ensino superior brasileiro, e o de no 19.852, que organizou a Universidade do Rio de Janeiro, ambos de 11 de abril de 1931, iniciaram o processo de estruturação, em moldes universitários, do ensino superior brasileiro.

Segundo a exposição de motivos do Ministro Francisco Campos, "A Universidade constituirá, assim, ao menos como regra geral, e em estado de aspiração enquanto durar o regime transitório de institutos isolados, a unidade administrativa e didática que reúne, sob a mesma direção intelectual e técnica, todo o ensino superior, seja o de caráter utilitário e profissional, seja o puramente científico e sem aplicação imediata, visando, assim, a Universidade, o duplo objetivo de equipar tecnicamente as elites profissionais do Pais e de proporcionar amliente propício às noções especulativas e desinteressadas, cujo iestino, imprescindivel à formação da cultura nacional, é o da constigação e da ciência pura. O projeto exige, para que se institutua a universidade, a incorporação de pelo menos três direitos de ensino superior, entre os mesmos incluídos os de Fato, de medicina e engenharia, ou, ao invés de um deles, a uldade de Educação, Ciências e Letras".?

Faculausência, até então no sistema de ensino superior, de a favoraes de filosofia e letras e das de ciências destinadas tura, em ensino e a pesquisa científica, deixou nossa culrepubli todo o Império e durante mais de 40 anos de regime renovacano, quase completamente fora dos movimentos de predoção científica que se operaram no mundo ocidental. A ficos minância dos estudos literários sobre os estudos cientído $\mathrm{Pais}$ permanecia tão fortemente marcada no sistema cultural do ais que as atividades científicas, embora tenham se alarga1901 tavelmente com a criação do Instituto de Manguinhos, em , permaneceram dispersas, em instituições especiais de vá-

15-4.31. Exposição de Motivos do Ministro FRANCISCO CAMPOS - D.o. de 
rias naturezas - museus, estações experimentais e laboratórios, sem atingir o ensino superior que se desenvolvia dentro dos quadros tradicionais. Exceção à regra encontramos na Escola de Medicina da Bahia que, sob a orientação de Nina Rodrigues, realizou pesquisas científicas na área das ciências naturais entre os anos de 1891 a 1905.

Foi, todavia, na Universidade de São Paulo, criada em 1934 por Armando Sales de Oliveira, e a primeira a se estabelecer sob o regime do Decreto n? 19.851 da Reforma Francisco Campos, que se despertou a necessidade de uma Faculdade destinada a ser um centro de cultura filosófica e literária e foco poderoso de atividades científicas. Entendiam seus organizadores que a Faculdade de Filosofia, Ciências e Letras, instituída não para ser apenas portadora mas criadora de cultura, devia organizar-se como um núcleo em que se tem de centrar a Universidade em torno e em função da qual se reorganizariam, pela base, as escolas profissionais.

As transformações políticas de 1937, infelizmente, alteraram os rumos da Universidade paulista, e as resistências que se ergueram impediram que a Faculdade de Filosofia exercesse, desde o seu início, o papel científico e cultural que lhe fora destinado como "alma mater" da organização universitária. A sua finalidade cultural seria realizada "dentro da Universidade", mas sem nenhuma articulação funcional no plano dos estudos com os demais institutos. Reduziram-se, assim, as novas Faculdades, a mais um curso profissional, que passou a congregar, a partir de 1964, a maior parcela da população universitária.

Os elevados princípios da Reforma Francisco Campos não foram suficientes para organizar, em moldes universitários, 0 sistema de ensino superior brasileiro. Novas Universidades foram criadas sem nenhuma função integradora. As escolas isoladas, cuja existência foi reconhecida como transitória, tornaram-se a regra comum e se expandiram de forma surpreendento. Basta que vejamos o número de estabelecimentos criados nos períodos abaixo indicados:

$\begin{array}{llr} & & \\ \text { De } 1808 \text { a } 1890 \ldots \ldots \ldots \ldots \ldots \ldots & 14 & 14 \\ \text { De } 1890 \text { a } 1930 \ldots \ldots \ldots \ldots \ldots & 72 & 86 \\ \text { De } 1930 \text { a } 1945 \ldots \ldots \ldots \ldots \ldots & 95 & 181 \\ \text { De } 1945 \text { a } 1960 \ldots \ldots \ldots \ldots \ldots & 223 & 404 \\ \text { De } 1960 \text { a } 1968 \ldots \ldots \ldots \ldots & 278 & 682\end{array}$


A Lei no 4.024, de 20 de dezembro de 1961, que fixou as Diretrizes e Bases de Educação Nacional também não alterou significativamente a estrutura fundamental do sistema de ensino superior. No seu Título IX, Cap. I, depois de definir o objetivo do ensino superior (art. 66), dispõe que "o ensino superior será ministrado em estabelecimentos agrupados ou não em Universidades, com a cooperação de institutos de pesquisa e centros de treinamento profissional" (art. 67). Fixou-se, assim, como regra, como norma geral, o que até então vinha sendo, de acordo com o Decreto n? 19.851, de abril de 1931, a exceção legalmente consentida: "O ensino superior no Brasil obedecerá, de preferência, ao sistema universitário, podendo ainda ser ministrado em institutos isolados..."

A Lei de Diretrizes e Bases, concebendo a universidade como mera reunião de escolas (art. 79), propiciando a criação de universidades rurais e outras de objetivo especializado (art. 79 , $\$ 10$ ), fragmentando a unidade funcional de ensino-pesquisa, oficializando um tipo de colégio nos moldes dos atuais "cursinhos", representou, conforme assinala Valnir Chagas, "imenso retrocesso na formulação adequada dos problemas mais urgentes da Universidade brasileira". ${ }^{9}$

\section{REFORMA UNIVERSITARRIA}

O sistema universitário brasileiro passa, sistematicamente, a ser objeto de análise crítica. Dentro da própria organização há consciência da necessidade de uma revisão urgente, revisão de fins, revisão de meios, de estrutura física, de administração, de relação aluno-professor.

Colocados os pontos negativos em evidência: caráter estanque das Universidades, insuficiência quantitativa da rede (apesar de enorme expansão nos últimos anos, feita pela mulplicação desordenada de unidades e conseqüente desperdício de recursos materiais e humanos), presença insignificante de efetivos escolares em ramos de ensino considerados prioritários em relação às necessidades do País, exames de acesso ao ensino superior altamente seletivo, falta de prédios e aparelhamentos adequados, cátedra vitalícia e currículos e programas

8 Fonte: Setor de Documentação e Informação do Departamento de
Assuntos Universitários do MEC. UFRGS CHAGAS, Valnir - A Luta pela Universidade do Brasil - MEC/ GS - 1967 - pág. 15. 
desatualizados, inicia-se novo processo de reformulação do ensino superior brasileiro. O Decreto-lei n? 53 , de 18 de novembro de 1966, fixa princípios e normas de organização das Universidades Federais, ressaltando a necessidade de integração de ensino e pesquisa, vedando a duplicação de meios para fins idênticos ou equivalentes a fim de assegurar unidade à fragmentada estrutura universitária. Para suprir lacunas, nele existentes, o Decreto-lei n? 252, de 28 de fevereiro de 1967, definiu o conceito de áreas básicas, impondo o sistema departamental e reduziu a autonomia de cátedra para integrá-la, definitivamente, no âmbito do departamento.

A reforma universitária, convertida numa das "urgências nacionais" e a limitação desses Decretos face à conjuntura do ensino superior brasileiro, levaram à instituição de um Grupo de Trabalho destinado "a estudar a reforma da Universidade brasileira, visando a sua eficiência, modernização, flexibilidade administrativa e formação de recursos humanos de alto nivel para o desenvolvimento do País" (art. 10 do Decreto n? 62.937, de 2 de julho de 1968).

Entenderam seus componentes que, no caso brasileiro, a Universidade dentre as suas múltiplas tarefas, deveria se encaminhar principalmente em função de um duplo papel: "como - lugar onde a cultura de um povo e de uma época tende a atingir a plenitude de sua autoconsciência" e em seus objetivos práticos "como lugar de produção da tecnologia, indispensável a uma sociedade que vive o momento crítico de seu desenvolvimento". Trata-se de inserir, no plano global de desenvolvimento do País, uma idéia concreta de universidade brasileira não como simples transmissora de uma cultura universal já existente, mas como a instituição responsável pela elaboração de uma nova cultura que lhe cabe descobrir, formular e transmitir.

Decorrente do relatório do Grupo de Trabalho, foram promulgadas, em 27 de novembro de 1968, respectivamente, as Leis n: 5.539 (que dispõe sobre o Estatuto do Magistério Superior) e a de no 5.540 (fixando normas de organização e funcionamento do ensino superior) que juntamente com os Decretos-leis no 464 e 465, de 11 de fevereiro de 1969, constituem, hoje, a legislação básica que rege o ensino superior brasileiro. Abrangendo os pontos críticos do sistema universitário, segundo - que preconiza o "Programa Estratégico do Desenvolvimento" e mais operacionalmente o relatório do Grupo de Trabalho, vem 
a reforma se processando em ritmo lento, face às resistências e dificuldades já esperadas, uma vez que atinge estruturas tradicionais e privilégios profundamente enraizados no sistema anterior. Entre o "período crítico" e o "período orgânico" como estabeleceu Turgot, ou entre a "idade da discussão e da tradição" como pretendia Bagehot, "certamente não se espera que a lei opere por si o milagre da transformação da universidade brasileira, mas venha acelerar o processo já desencadeado". 10

O modo pelo qual o ensino superior se instituiu no Brasil como fenômeno histórico, mais uma conseqüência das condif̧ões e possibilidades da sociedade estabelecida do que como resultado de acidentes, segundo julgam alguns, nos leva a crer que a Reforma - contestação e busca de uma verdadeira concepção de Universidade - assume, no momento, a maior importância, identificando-se, enfim, ao tempo sócio-cultural da mudança que caracteriza a realidade brasileira.

10 SUCUPIRA, Newton - A Reestruturação das Universidades Federais - Rev. bras. Est. Ped. no 111 - Rio de Janeiro - MEC/INEP - 1968 Pág. 87. 


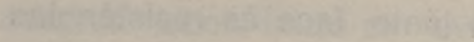

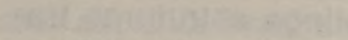
and

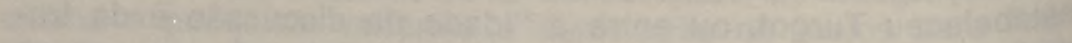

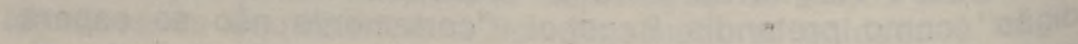

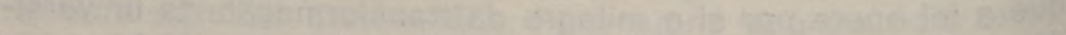

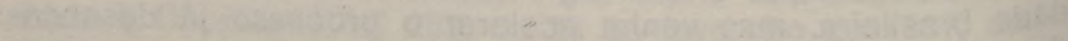
$+\frac{1}{2}$

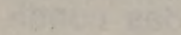

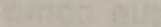

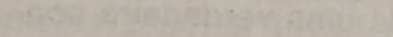

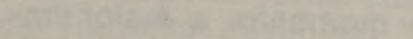

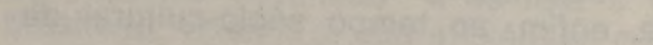

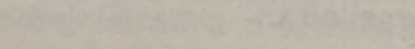
$x^{2}=x^{2}$ 